\title{
Morbidity trends in the population of a specialised homeless primary care service
}

\author{
Nigel Hewett, Anna Hiley and Jane Gray
}

\begin{abstract}
An increasing body of research demonstrates that homelessness is an independent risk factor for morbidity and premature death. This paper compares the frequency of diagnoses between 2003 and 2009 in the computerised records of a specialist practice for homeless people. The changing morbidity trends revealed offer a basis for comparison with other services and suggest benefits from collaborative working, particularly around substance misuse and mental health.

Keywords

homeless persons; morbidity; treatment outcome; trends;
\end{abstract}

N Hewett, OBE, FRCGP, medical director, London Pathway; A Hiley, MRCGP, medical director, Inclusion Healthcare; J Gray, BSc, QN, director of nursing and development, Inclusion Healthcare, Dawn Centre, Leicester.

Address for correspondence

Dr Nigel Hewett, Inclusion Healthcare, Dawn Centre,

Conduit Street, Leicester, LE2 0JN.

E-mail: nigelhewett@nhs.net

Submitted: 2 June 2010; Editor's response: 21 July 2010; final acceptance: 13 August 2010.

(OBritish Journal of General Practice 2011; 61: 200-202.

DOI: 10.3399/bjgp11X561203

\section{INTRODUCTION}

National economic analysis shows that homeless people are high users of unscheduled care, with five times the accident and emergency (A\&E) attendances, 3.2 times the admissions, three times the duration of stay, and eight times the secondary care costs of the housed population. This is associated with an average age of death between 40 and 44 years. ${ }^{1}$ Canadian research shows a two in three chance of a 25-year-old Canadian male living to the age of 75 years, this is reduced to one in three among 25-year-old residents of shelters or rooming houses. ${ }^{2}$ A study of hospital admissions in Glasgow found that a homeless patient admitted with a drugrelated problem was seven times more likely to die over the next 5 years than a housed patient admitted with the same drug-related diagnosis. ${ }^{3}$

The Cabinet Office Social Exclusion Task Force and the Department of Health have recently published a study called Inclusion Health, which aims to encourage the commissioning of services for socially excluded groups, such as homeless people. ${ }^{4}$ Over the years, specialist homeless primary care services have been developed in some areas to try and meet the particular healthcare needs of the homeless population, but there are few data available on the outcomes of these developments.

A full-time specialist primary healthcare service for homeless people in Leicester was set up in March 2000. This followed a needs assessment and research seeking the opinions of homeless people. ${ }^{5}$ Over 10 years, the service has grown to include a full team of nurses and GPs, with dedicated drug and alcohol workers, a sessional counsellor, aromatherapist, and optician, and a mental health team including community psychiatric nurses, a psychologist, and consultant sessions. Since 2006 the service has been provided from new one-stop shop premises, that include a drop-in centre run by the YMCA, which also serves as the practice waiting area, and a 42-bed shelter run by the local authority. A weekly multi-agency meeting coordinates care between front-line agencies for the hardest to reach of the homeless population. ${ }^{6}$ This report aims to 
compare diagnoses of attenders between 2003 and 2009.

\section{METHOD}

Annual reports are used to publish progress reports on the developing service, results of audits, and patient satisfaction surveys. A full morbidity survey of all computerised diagnoses did not alter significantly over the first few years so was last carried out in 2003. This survey was repeated in 2009 to look for any changes. The trends in infestation rates were particularly striking, so an additional annual analysis of recorded cases of head and body lice and scabies for each year from 2001 to 2009 was carried out.

\section{RESULTS}

The practice population stabilised within a year, at around 9000 annual consultations for 1000 patients. With a $59 \%$ annual patient turnover, the total number of different patients seen over the 9 years to March 2009 was 4407 . Almost all patients are in the age range 17 to 64 years, and $15.8 \%$ are female. Fifty-three per cent of the practice patients were born in Leicester and another $33 \%$ elsewhere in the UK, so this is a service largely for a local population; $65 \%$ were unable to work due to long-term sickness and $74.7 \%$ reported a longstanding illness, disability, or infirmity.

\section{How this fits in}

These data confirm that patients attending a practice for homeless people experience disproportionately high levels of physical and mental ill health and premature death. However positive trends have emerged for example in

infestation rates and episodes of suicide and self-harm, suggesting benefits from multi-agency working. Forthcoming cuts to budgets across social care, health and housing are widely predicted to result in increasing numbers of homeless

people. As GP commissioning groups begin to form it will be important to consider the particular needs, and associated high healthcare costs, resulting from poverty and social deprivation.

The incidence of main diagnoses between 2003 and 2009 is shown in Table 1, while Figure 1 show changes in infestation rates over time. These encouraging trends are probably due to a combination of improved access to treatment, with reductions in rough sleeping and improved hostel conditions.

\section{Mortality data}

The age and cause of death for patients treated by the service has been recorded since 1989. The average age at death for these 131 patients is 40.5 years. Alcohol is implicated as a cause of death for 62 (47.3\%) clients, and 13 of these deaths were in combination with other drugs. Accidental overdose of drugs of abuse is implicated as a cause of death for 32

Table 1. Incidences of main diagnoses between 2003 and 2009.

\begin{tabular}{|c|c|c|}
\hline Diagnosis & $\begin{array}{l}\% \text { consulting in year to March } \\
2003 \text { and ever diagnosed }\end{array}$ & $\begin{array}{l}\text { \% consulting in year to March } \\
2009 \text { and ever diagnosed }\end{array}$ \\
\hline Depression & 26 & 29.7 \\
\hline Anxiety & 9 & 15.3 \\
\hline Personality disorder & 5 & 7.7 \\
\hline Schizophrenia & 2.8 & 2.2 \\
\hline Learning difficulty & 2 & 3.3 \\
\hline Heroin dependence & 37 & 28 \\
\hline Benzodiazepine dependence & 2.7 & 1.7 \\
\hline $\begin{array}{l}\text { Proportion of patients with drug dependency } \\
\text { ever treated by the service }\end{array}$ & 37 & 66 \\
\hline Alcohol dependence & 20 & 29 \\
\hline Fractures & 8.3 & 28.6 \\
\hline Assault & 10.7 & 17.5 \\
\hline Suicide attempt/self-harm & 8.4 & 3.0 \\
\hline Upper gastrointestinal disease & 12 & 13.6 \\
\hline Asthma & 14 & 16 \\
\hline Chronic obstructive pulmonary disease & 2 & 1.7 \\
\hline Tuberculosis & 0.9 & 0.6 \\
\hline Smoking data recorded & 10 & 78 \\
\hline Eczema & 3.7 & 18.5 \\
\hline Hepatitis C & 7.4 & 11.3 \\
\hline Hepatitis B & 0.5 & 2 \\
\hline HIV/AIDS & 0.1 & 0.5 \\
\hline
\end{tabular}




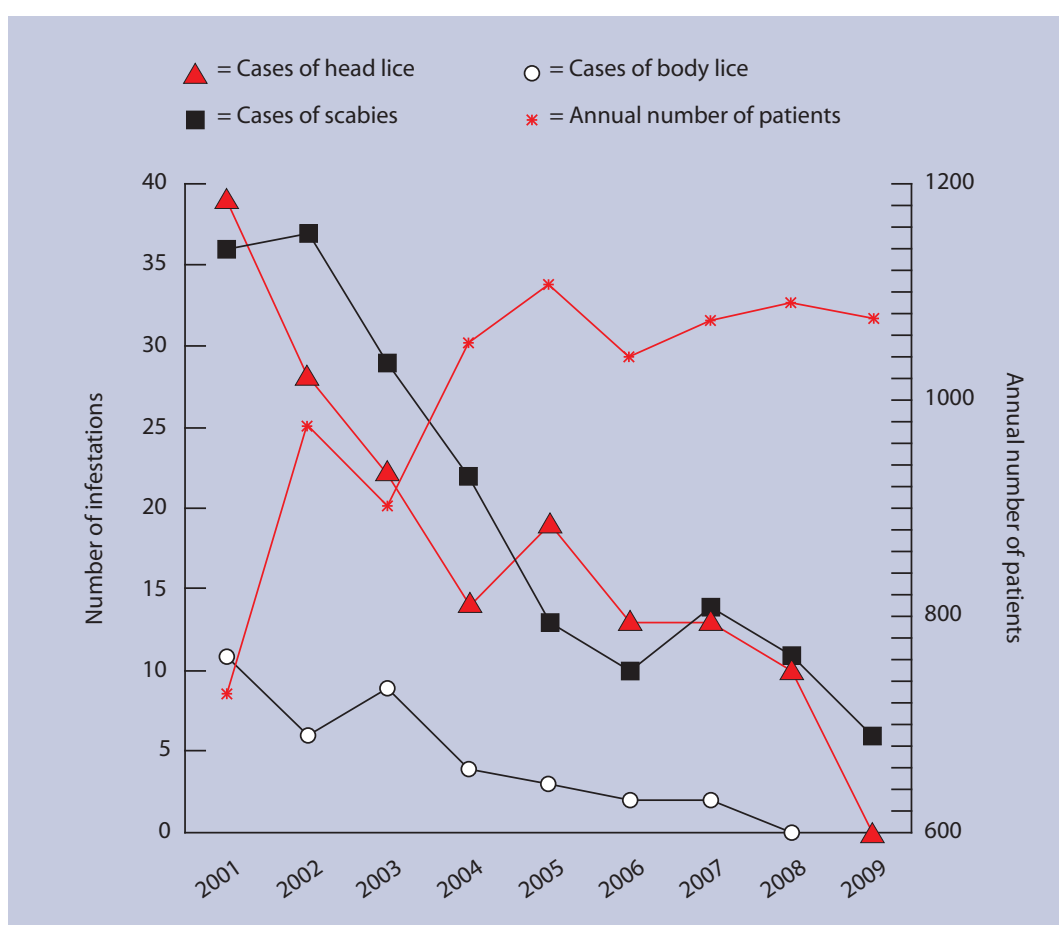

Figure 1. Infestation rates over time.
(24.4\%) clients. Deliberate suicide by overdose or other means is implicated for $10(7.6 \%)$ clients. These mortality data are within national parameters. ${ }^{1}$

\section{DISCUSSION}

\section{Summary of main findings}

All of these data need to be understood in the context of poverty: Leicester City is ranked as the 20th most deprived local authority in the country. High annual turnover means that increasing diagnostic rates are not caused by more data accumulated on a stable population. However improved summarising of paper records driven by Quality and Outcomes Framework targets have improved computerised recording of smoking data and past diagnoses that clinicians would not routinely record, such as eczema and hospital attendances for fracture and assault.

The frequencies of mental health diagnoses such as depression and schizophrenia are stable. Despite an increase in diagnoses of anxiety there is a marked drop in episodes of self-harm and suicide attempts. This probably reflects improved access to psychiatric help through homeless mental health and crisisresolution teams.

\section{Strengths and limitations of the study}

These diagnoses were made by stable clinical teams as part of routine clinical practice and recorded using the same clinical computer system over the period studied. The effects of paper notes summarising and Quality and Outcomes Framework requirements are clear, while the changes in drug and alcohol dependence recorded tend to confirm national trends.
However, the other changes observed could have resulted from chance or some other factor not associated with healthcare delivery.

\section{Comparison with existing literature}

A reduction in the proportion of patients ever diagnosed with heroin dependency is in keeping with national trends and the increase in dependent patients ever treated for dependency by the Leicester service reflects both easy access to treatment and a maturing population of heroin users, with fewer young patients taking up this habit. The increase in alcohol dependency is also in keeping with national trends and confirms a shift from heroin to alcohol as the most prevalent drug of dependency among the homeless population.

\section{Implications for clinical practice}

This morbidity data provides a baseline for comparison with other services and suggests some trends, which should influence service planning and commissioning. Alcohol has overtaken heroin as the most problematic drug of addiction for the homeless population. The authors suggest that consistent provision of drug treatment in this setting contributes to an increasing proportion of patients receiving treatment and an overall reduction in heroin dependency. A similar approach should be considered for alcohol dependency. While severe and enduring mental illness diagnoses are stable, anxiety and depression are increasing. Despite this observation, the proportion of patients who have ever self-harmed or attempted suicide has reduced, suggesting potential benefits from a multi-agency approach to mental health problems.

\section{Competing interests}

The authors have stated that there are none.

\section{Discuss this article}

Contribute and read comments about this article on the Discussion Forum: http://www.rcgp.org.uk/bjgp-discuss

\section{REFERENCES}

1. Office of the Chief Analyst. Healthcare for single homeless people. London: Department of Health, 2010.

http://www.dh.gov.uk/en/Publicationsandstatistics/Publications/Publica tionsPolicyAndGuidance/DH_114250 (accessed 25 Jan 2011).

2. Hwang SW, Wilkins R, Tjepkema M, et al. Mortality among residents of shelters, rooming houses and hotels in Canada: 11 year follow-up study. BMJ 2009; 339: b4036.

3. Morrison DS. Homelessness as an independent risk factor for mortality: results from a retrospective cohort study. Int J Epidemiol 2009; 38(3): 877-883.

4. Department of Health. Primary care \& community services. Inclusion health: improving primary care for socially excluded people. London: TSO 2010.

http://www.dh.gov.uk/prod_consum_dh/groups/dh_digitalassets/@dh/ @en/@ps/documents/digitalasset/dh_114365.pdf (accessed 9 Feb 2011).

5. Hewett N. How to provide for the primary health care needs of homeless people: what do homeless people think? Br J Gen Pract 1999; 49(447): 819 .

6. Hewett N. In from the cold. Health Serv J 1998; 108(5627): 30-31. 